\title{
An Important but Overlooked Measure for Containing the COVID-19 Epidemic: Protecting Patients with Chronic Diseases
}

\author{
Jing $\mathrm{Wu}^{1, *}$
}

The COVID-19 outbreak has rapidly spread around the world over the past several weeks. On March 11, 2020, the World Health Organization designated it as pandemic (1) and as of 23:59 CET March 19, 2020, there were a total of 234,073 confirmed cases and 9,840 deaths in 176 countries, areas, or territories (2). The COVID-19 global pandemic posts a significant global public health challenge to every individual around the world (3-4).

Eliminating sources of infection, cutting off routes of transmission, and protecting susceptible populations are routine measures for containing infectious diseases. At present, our understanding of the COVID-19 virus and its transmission is deepening, and scientists are racing to develop effective vaccines and drugs. In this context, protection of susceptible and vulnerable people is extremely important, especially for patients with underlying chronic diseases.

In China, more than 300 million individuals are living with a chronic disease or condition (5). Patients with chronic diseases, such as cancer, chronic obstructive pulmonary disease (COPD), cardiovascular diseases (CVDs), or diabetes, will have more serious consequences and need more complex treatment if they become infected with COVID-19. These patients are at extremely high risk of complications and death (6-8).

Patients with chronic diseases experience dilemmas. Their conditions require routine medical follow-ups and services where they may be more likely to be exposed to the virus when they visit clinics and hospitals. Likewise, if they do not go to clinics and hopitals for treatment due to city orders for social distancing and isolation during a public health emergency, they may not get timely and effective medical attention, resulting in increased risk of complications and even death (9-11).

In addition, patients with chronic disease who contract COVID-19 are also likely to spread the virus to their caretakers and signs and symptoms caused by the virus may be masked by their preexisting conditions or symptoms.
On the upside, patients with chronic diseases usually pay more attention to their own health or are cared for with personal protective equipment. They may have more health awareness and knowledge and are more compliant with epidemic prevention and control measures. These patients usually have more complete medical records, which are more helpful for epidemiological investigations.

We therefore make the following recommendations:

When preparing and respondiong to a potential public health emergency, local authorities shall fully identify the number of patients with chronic disease, estimate potential needs and demands, and fully consider the drug stockpile and medical resources.

Center for Disease Control and Prevention (CDC) and professional organizations should issue general protection guidance or guidelines for patients with chronic diseases, make every effort to promote their protection awareness and knowledge, and alert them to reduce external activities during the epidemic period and actively seek psychological consultations to relieve stress and anxiety.

Hospitals should take into consideration of patients' comorbidities when formulating criteria of diagnosis, differential diagnosis, and referral and discharge for infectious diseases.

Authorities should take comprehensive measures through hospitals, medical insurance, and community and disease control agencies to ensure that patients with chronic diseases can continue receiving proper diagnosis and treatment services such as medication prescriptions and retrieval with little interruption when they visit hospital or clinics and timely consultation and guidance from healthcare providers in case of emergencies.

Hospitals should develop and implement telemedicine and other forms of long-distance capacity to maintain communication with patients with chronic diseases. Community health centers should provide regular and sub-urgent care services for patients with chronic diseases nearby.

Health insurance departments should adjust 
regulations allowing patients with stable chronic diseases to have prescription drugs extended up to 90 days.

In conclusion, in case of public health emergencies, protecting patients with chronic conditions requires significant and relevant public health consideration. Multi-departmental coordination and efforts are needed to safeguard the health and wellbeing of patients with underlying chronic diseases.

Acknowledgement: The author would like to thank all of those fighting COVID-19 on the frontlines home and abroad.

\# Corresponding author: Jing Wu, wujing@chinacdc.cn.

\begin{abstract}
National Center for Chronic and Non-Communicable Disease Control and Prevention, Chinese Center for Disease Control and Prevention, Beijing, China.
\end{abstract}

Submitted: March 21, 2020; Accepted: March 22, 2020

\section{REFERENCES}

1. World Health Organization. Virtual press conference on COVID-19 11 March 2020. 2020. https://www.who.int/docs/default-source/corona viruse/transcripts/who-audio-emergencies-coronavirus-press-conferencefull-and-final-11 mar2020.pdf?.sfvrsn=cb432bb3_2. [2020-03-11].

2. World Health Organization. Novel coronavirus (COVID-19) situation. 2020. https://experience.arcgis.com/experience/685d0ace521648f8a5be eeee1b9125cd. [2020-03-20].
3. Mahase E. Coronavirus: covid-19 has killed more people than SARS and MERS combined, despite lower case fatality rate. BMJ 2020; 368:m641. http://dx.doi.org/10.1136/bmj.m641.

4. Sands P, EI Turabi A, Saynisch PA, Dzau VJ. Assessment of economic vulnerability to infectious disease crises. Lancet 2016;388(10058): 2443 - 8. http://dx.doi.org/10.1016/S0140-6736(16)30594-3.

5. National Health and Family Planning Commission. 2014 report on Chinese resident's chronic disease and nutrition. People's Medical Publishing House. 2015. http://www.chinadaily.com.cn/m/chinahealth/ 2015-06/15/content_21008408_2.htm.

6. Zhu N, Zhang DY, Wang WL, Li XW, Yang B, Song JD, et al. A novel coronavirus from patients with pneumonia in China, 2019. N Engl J Med 2020;382(8):727 - 33. http://dx.doi.org/10.1056/NEJMoa20010 17.

7. Wu ZY, McGoogan JM. Characteristics of and important lessons from the coronavirus disease 2019 (COVID-19) outbreak in China: summary of a report of 72314 cases from the chinese center for disease control and prevention. JAMA 2020. http://dx.doi.org/10.1001/ jama.2020.2648.

8. Huang CL, Wang YM, Li XW, Ren LL, Zhao JP, Hu Y, et al. Clinical features of patients infected with 2019 novel coronavirus in Wuhan, China. Lancet 2020;395(10223):497 - 506. http://dx.doi.org/10.1016/ S0140-6736(20)30183-5.

9. Weston D, Hauck K, Amlôt R. Infection prevention behaviour and infectious disease modelling: a review of the literature and recommendations for the future. BMC Public Health 2018;18(1):336. http://dx.doi.org/10.1186/s12889-018-5223-1.

10. Zheng YY, Ma YT, Zhang JY, Xie X. COVID-19 and the cardiovascular system. Nat Rev Cardiol 2020. http://dx.doi.org/10. 1038/s41569-020-0360-5.

11. Ji YP, Ma ZR, Peppelenbosch MP, Pan QW. Potential association between COVID-19 mortality and health-care resource availability. Lancet Glob Health 2020;8(4):PE480. http://dx.doi.org/10.1016/ S2214-109X(20)30068-1.

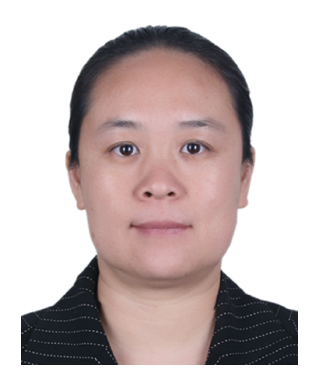

Jing WU, MD, PhD

Director, National Center for Chronic and Non-Communicable Disease Control and Prevention, Chinese Center for Disease Control and Prevention, Beijing, China 